\title{
The Adoption of Mobile Commerce Service among Employed Mobile Phone Users in Bangladesh: Self-efficacy as A Moderator
}

\author{
Md. Aminul Islam \\ School of Business Innovation and Technopreneurship, University Malaysia Perlis \\ E-mail: amin_shanto@yahoo.com \\ Mohammad Aktaruzzaman Khan \\ International Islamic University \\ Chittagong, Bangladesh \\ E-mail: rajarkul2002@yahoo.com
}

T. Ramayah

School of Management, University Sains Malaysia

Penang, Malaysia

E-mail: ramayah@gmail.com

Muhammad Muazzem Hossain

School of Business, Grant MacEwan University

10700 - 104 Ave, Edmonton, AB T5M 3L5, Canada

Tel: 1-780-633-3514Ｅ-mail: HossainM4@macewan.ca

Received: January 19, 2011 Accepted: January 30, 2011 doi:10.5539/ibr.v4n2p80

\begin{abstract}
Mobile commerce or better known as M-commerce is a fairly new phenomenon in the wake of the second technology wave from the famous E-commerce (electronic commerce) in the $21^{\text {st }}$ century. As the Internet started to proliferate in many parts of the world, the mobile phone penetration in terms of voice communication started to grow rapidly. This simultaneous rapid growth has caused a new phenomenon of convergence of Internet computing and mobile communication where M-commerce has its root. M-commerce has the potential to enhance the work-life within the employed mobile phone users in Bangladesh. The purpose of this study is to examine whether awareness and knowledge, convenience of Mobile devices and WAP/GPRS enabled handsets, pricing and cost, security and privacy, rich and fast information, and perceived usefulness have any influence on the adoption of M-commerce among employed Mobile phone users in two major cities in Bangladesh - Dhaka and Chittagong. A survey method was used to collect data. The findings suggest that pricing and cost, rich and fast information, and security and privacy are significant predictors of the adoption of M-commerce. Self-efficacy is found to be a moderating factor for the adoption of M-commerce services.
\end{abstract}

Keywords: Mobile commerce, Adoption level, M-commerce services, Self-efficacy, Bangladesh

\section{Introduction}

The convergence of the two fastest growing industries - the internet and the mobile communication - has led to the creation of an emerging market for mobile commerce (M-commerce). Although the M-commerce market is relatively young, mobile online shopping is rapidly reaching a critical mass of businesses and individual users. In 2009 , mobile online shopping increased more than threefold to $\$ 1.2$ billion in the U.S. and exceeded $\$ 10$ billion in Japan. By the end of 2010, M-commerce market in Europe is expected to outpace that in the U.S. Analysts expect that worldwide mobile online shopping will reach $\$ 119$ billion in 2015 (ABIresearch, 2010). M-commerce contributes the potential to deliver the most of what the internet can offer plus the advantage of mobility. 
M-commerce gives mobile communication devices such as mobile phones and personal digital assistants (PDA) the ability to pay for goods and services.

M-commerce is difficult to define and can be interpreted in a variety of ways. This is because M-commerce is a fairly new phenomenon and several definitions of it exist. M-commerce can be defined as "all activities related to a (potential) commercial transaction conducted through communication networks that interface with wireless devices". Another definition of M-commerce is "the use of wireless device to communicate, interact, and transact via high speed communication to the internet" (Shuster, 2001, p. 2). Angsana (2002) emphasizes on three elements of M-commerce - a range of activities, devices, and network types - and defines M-commerce as "all electronic transactions (e.g., communication interaction, purchase, payment) that use data-enabled wireless device connection to the internet or to a vendor's private network" (p. 8).

However, the real value of M-commerce lies in its ability to realize the tremendous business opportunity and address lifestyle issues prevalent in an aware, hyper-efficient, "on always" world. Mobile values or m-value signifies the value arising from the mobility of the new medium, i.e., making use of the internet connection while on the move. M-commerce has, in fact, been defined as "an e-commerce for users on the move" (Vitter-Pillippe and Navarro, 2000). With the relatively new emergence of M-commerce from the simple service of SMS to mobile payment, service vendors are cautious in introducing more complex transactions in providing alternative payment services so as not to oversell its potential. Some vendors have rolled out such services to the market on a very small scale and within a somewhat restricted environment. As the mobile commerce industry is still in its infancy, there are many unsolved problems related to its services. One major issue is the development of service that is able to support the diverse array of mobile devices and multiple networks, and provide a foolproof security to consumers. Furthermore, software and interface vary among different suppliers. Nevertheless, many industry and technology leaders are addressing these problems and thus M-commerce has a great potential as the era of wireless and mobility becomes a trend in the $21^{\text {st }}$ century.

In Bangladesh, there is a growing number of wireless technology users in the area of M-commerce. There are more consumers who have a mobile phone than those who have a personal computer. Despite the rapidly growing number of mobile phone users in Bangladesh, M-commerce is a relatively new phenomenon in Bangladesh compared to other markets in Europe, the U.S., and the Asia Pacific. The M-commerce service providers in Bangladesh lack a clear direction toward understanding the factors affecting the adoption of M-commerce. Therefore, the objective of this study is to explore the factors that influence the adoption of M-commerce services among mobile users in Bangladesh.

The rest of the paper is organized as follows: a brief overview of the telecommunication industry in Bangladesh is presented followed by literature review, research model, proposed hypotheses, research methodology of the study, analyses and results, and discussion and conclusion of the major findings. We end the paper with a section on the limitations and future direction of the study.

\section{Overview of the Telecommunication Industry in Bangladesh}

Currently, there are six mobile phone operators offering their services to customers in Bangladesh. The total number of mobile phone subscribers has reached 43.7 million at the end of June of 2008 (BTRC, Annual Report, 2007-2008). GrameenPhone (GP) owned by Telenor (62\%) and Grameen Telecom (38\%) is the largest and the fastest growing cellular service provider in Bangladesh. BanglaLink is the second largest cellular service provider. It is a wholly owned subsidiary of Orascom Telecom. Aktel Malaysia International Bangladesh (TIMB) Limited is the $3^{\text {rd }}$ largest cellular service provider in Bangladesh. It is a joint venture between Telecom Malaysia Sdn Bhd of Malaysia (70\%) and a local company A.K. Khan \& Company (30\%). The fourth largest cellular sevice provider in Bangladesh is Warid Telecom International Ltd. Warid Telecom is a wholly owned subsidiary of Warid Telecom International LLC, Abu Dhabi. The other two mobile phone operators in Bangladesh are Citycell and Teletalk Bangladesh Ltd. Table 1 summarizes the number of mobile phone subscribers for these operators. Table 2 provides a summary of the value added service offered by mobile phone operators in Bangladesh.

\section{Literature Review}

The development of M-commerce started in a very unique way. Although the United States has more PCs per 100 inhabitants compared to many countries, it is far behind Europe and Asia with respect to cellular phone users (Haque, 2004). The popularity of mobile phone among Europeans and Asians has caused the transition of e-commerce from a PC-based internet service to a mobile phone internet service. Europe leads the mobile market and the M-commerce. A number of factors have contributed to Europe's position in leading the M-commerce market. These factors include favorable pricing structure, increasing competition in greater quality of service, and declining costs of network operators (Rao, 2002). However, in the emerging markets such as Africa, Asia Pacific, Latin America and the 
Middle-East, the mobile market is expected to grow at a compounded annual growth rate (CAGA) of 16.2 percent. Asia Pacific is forecasted to be the world's largest market for mobile terminal with over 1.3 billion phone subscribers by 2010 (Gartner Dataquest, 2005).

\subsection{M-commerce Services}

The M-commerce services can be classified according to end user types such as $\mathrm{B} 2 \mathrm{C}, \mathrm{C} 2 \mathrm{C}$, and $\mathrm{B} 2 \mathrm{~B}$. The majority of the existing mobile commerce services deal with an exchange of product, service or information in the B2C context (Panis et al., 2001). These services include mobile financial service, user and location specific mobile advertising, mobile inventory management, wireless business re-engineering, and mobile interactive games. In addition to the device and wireless constraints, M-commerce is also impacted by the wireless infrastructure. The existing and future services of M-commerce include mobile banking service (e.g., check account information, money transfer), mobile trade service (e.g., stock quotes, selling/buying), credit card information (e.g., account balance), airline services (e.g., online reservation, timetable), travel, concert ticket reservation, sales, entertainment, news/information, database, and location based applications.

Since M-commerce is a fairly new phenomenon, several different types of services exist in the academic and practitioner literature. The list is still growing as new services are being recommended. According to Leung, Chan and Chan (2003), M-commerce applications are basically divided into three main types: (1) purchase of physical goods that requires some kinds of information distribution to complete the transaction, (2) purchase of services such as selling and buying stocks, and (3) information delivery such as news headline and stock market information. However, the mobile commerce services may be categorized into four main categories: (1) entertainment services (music, games, graphic, video and TV streaming), (2) communication services (short messaging, unified messaging, e-mail, chat rooms and video conferencing), (3) transaction services (banking, brokerage, shopping, auctions, betting, booking and reservations, mobile wallet, voting, and competition/contests), and (4) information services (news, city guide, directory service, maps, traffic and weather, corporate information, market data and mobile advertising).

\subsection{Factors Affecting the Adoption of M-commerce Services}

Adoption is an individual's decision to become a regular user of a product or a service. This study explores the factors that influence the adoption of M-commerce service among working employed users in Bangladesh. Numerous studies have been conducted around the world on the adoption of M-commerce (e.g., Jillbert and Khasawneh, 2003; Haque, 2004; Mariga, 2003; Huei, 2004; Bax and McGill, 2002; Vrechopoukis et al., 2002). Jillbert and Khasawneh (2003) suggest that low risk, rich information, low cost, social influence awareness and user satisfaction are the significant predictors of the adoption of M-commerce services. Haque (2004) suggests that ease of use, portals and search engines, content with graphics and interactivity, packet switching technology and bandwidth, payment trust and legality, mobile commerce and web enable handsets, non intrusive personalization, timeless and cost effectiveness influence the adoption of M-commerce. Mariga (2003) posits that perceived usefulness, perceived ease of use, trust, and enjoyment is the significant determinant for the adoption of M-commerce services. Huei (2004) suggests that perceived usefulness, perceived ease of use, perceived risk, and cost is the influencing factors for the adoption of M-commerce. Bax and McGill (2002) suggest that perceived usefulness, computer self efficacy, computer anxiety, and internet self efficacy are the most important factors affecting the adoption of M-commerce. According to Vrechopoukis et al. (2002), the ease of user interface, security, customer service awareness, price, and comfort of device influence the adoption of M-commerce among customers.

\subsection{Self-efficacy as a Moderator}

According to Wooe and Bandura (1989), self-efficacy refers to "beliefs in one's capabilities to mobilize the motivation, cognitive resources, and courses of action needed to meet given situational demands". Perceived self-efficacy plays an important role in affecting motivation and behavior. The self-efficacy theory (Bandura, 1977) suggests that there are four source areas of information used by individuals when forming self-efficacy judgments. They are performance accomplishments, vicarious experience, verbal persuasion, and physiological state. Consumers who consider M-commerce too complex and believe that they will never be able to master the M-commerce technology will prefer to avoid them and are less likely to use them. Gist (1989) suggests that self-efficacy is an important motivational variable, influencing effort persistence and motivation. In addition, individuals who feel less capable of handling a situation may resist it because of their feelings of inadequacy or discomfort. On the other hand, individuals with high self-efficacy will perceive the use of M-commerce to be user friendly and easy to use due to the effect of self-efficacy on the degree of effort, the persistence and the level of learning (Bandura, 1977), and will be less resistant to changes. Hence, self-efficacy will affect beliefs and behavior of consumers adopting M-commerce services through either direct or indirect usage factors. 


\section{Research Model}

The extant literature (e.g., Hossain and Prybutok, 2008; Jillbert and Khasawneh, 2003; Haque, 2004; Mariga, 2003; Huei, 2004; Bax and McGill, 2002; Vrechopoukis et al., 2002; Electronic Commerce Resource Center of Thailand, 2002; Davis, 1989) reveals that a number of factors impact the successful adoption of M-commerce. In consistent with the literature, this study posits that awareness and knowledge, convenience of mobile and WAP/GPRS enabled device, pricing and cost, security and privacy, rich and fast information, and perceived usefulness are the critical factors that impact the adoption of M-commerce. Self-efficiency is selected as the moderating variable based on Rosa, Marisa and Maria (2001). The research model is presented in Figure 1.

\section{Hypotheses}

As depicted in the research model (see Figure 1), we propose the following hypotheses:

\subsection{Awareness and Knowledge}

Jillbert and Ahmad (2003) conducted a study in Australia, and used the awareness and knowledge about the mobile commerce services as one of the factors affecting the adoption of M-commerce services. Based on this study, we formulate the following hypothesis:

H1: Consumers with a high awareness and knowledge of M-commerce services will be more likely to adopt M-commerce services.

\subsection{Convenience}

People tend to adopt a technology if they perceive that the technology makes their life more convenient. (Hossain and Prybutok, 2008). Tang and Veijalinen (2001) assert that the main force for rapid acceptance rate of M-commerce is its increasing convenience and efficiency in performing simple transactions compared with the stationary machines. However, the comfort level of using the input mechanisms, screen resolution, and screen size of the mobile phones are critical physical make-up of the mobile phone which makes it easier for the user to navigate and perform any M-commerce transaction. In addition, having WAP/GPRS enabled in the mobile phone plays a critical role in enabling M-commerce applications. Thus, we propose the following hypothesis:

H2: Convenience of mobile and WAP/GPRS enabled devices will increase the likelihood of consumer adoption of M-commerce services.

\subsection{Cost and Pricing}

Heinonen (2002) conducted a study on the acceptance of mobile services and suggests that the pricing of the M-commerce services is one of the most significant factors affecting the use of mobile services. The research findings from Swedish market also posit that too high prices for the mobile services hinder the use of those services. Following this argument, the following hypothesis can be proposed:

H3: The lower the cost and pricing of using M-commerce service the more likely the services will be adopted.

\subsection{Security}

Consumer acceptance of a technology is influenced by how consumers view the importance of security and how willing they are to sacrifice security against the benefits derived from the use of the technology (Hossain and Prybutok, 2008). Therefore, the lack of wireless security standard and practices could inhibit the rapid adoption of M-commerce in the region. Thus, the following hypothesis is proposed:

H4: The lower the perceived risk from security issues of using mobile commerce services the more likely the service will be adopted.

\subsection{Rich and Fast Information}

Jellbert and Ahmad (2003) suggest that the minimal textual display on the mobile devices is one of the reasons that can lead to the introduction of other inhibitors to M-commerce adoption. Furthermore, the speed and timeliness of getting the information is also important for users to adopt M-commerce services. Thus, the following hypotheses can be postulated:

H5: The higher the perception of rich and fast information the more likely the adoption of M-commerce services among consumers.

\subsection{Usefulness}

The Technology Acceptance Model (TAM) is one of the most influential extensions of Ajzen and Fishbern's Theory of Reasoned Actions (TRA) in the information system literature. TAM used the generic Fishbein and Ajzen's TRA model (Fishbein \& Ajzen, 1975) to the particular domain of user acceptance of computer technology, replacing the 
TRA's attitudinal determinants with two specific behavioral beliefs: perceived ease of use and perceived usefulness in a technology acceptance measures. Perceived usefulness is defined as "the degree to which a person believes that using a particular system would enhance his or her productivity" (Davis, 1989, p. 320). Huei (2004) posits perceived usefulness has a significant positive influence on the acceptance of the wireless computing devices. This factor was also used by Bax and McGill (2002) in their study on Web Application on Mobile Computing, where Perceived Usefulness was used as an independent variable. These suggest that people who perceive the wireless computing devices are useful tend to accept the wireless computing devices.

H6: The Perceived Usefulness in M-commerce services has a significant influence in the adoption of M-commerce services.

\subsection{Self-efficacy}

Rosa, Marisa and Maria (2001) found the moderator effect of self-efficacy on occupational stress. They examined self-efficacy as a moderator and found that self-efficacy moderates the stress-strain relationship, suggesting that low level of self-efficacy is related to high level of occupational stress in adopting new technology. We, therefore, posit that the degree of self-efficacy of a consumer will have a moderating effect on the adoption of M-commerce services. The following hypotheses are proposed to test the moderating effects of self-efficacy on the relationships between the independent variables and dependent variable.

H7: The positive relationship between awareness and knowledge, and intention will be stronger when self efficacy is higher.

H8: The positive relationship between Convenience of Mobile Devices and WAP/GPRS enabled handset, and intention will be stronger when self efficacy is higher.

H9: The positive relationship between Pricing and Cost, and intention will be stronger when self efficacy is higher.

H10: The positive relationship between Security and Privacy, and intention will be stronger when self efficacy is higher.

H11: The positive relationship between Rich and Fast information, and intention will be stronger when self efficacy is higher.

H12: The positive relationship between Perceived Usefulness and intention will be stronger when self efficacy is higher.

\section{Research Methodology}

A survey method was used to collect the data for the study. The instrument was developed from an earlier work by Loh (2004). The items were adapted to suit an audience more familiar with the actual situation in Bangladesh. Initial pilot testing was performed on a limited audience to verify that the modifications do not adversely affect the validity of the questionnaire. A total of 40 responses were received for the pilot test. The findings of the pilot test were used to finalize the instrument. The survey was administered to various working segments in Dhaka and Chittagong - two major cities of Bangladesh. Primary means of distribution was the hardcopy delivery of the survey questionnaires. Participants were chosen at random. The questionnaires were distributed after meeting the recipients and informing them the objectives of the survey. One hundred and ten questionnaires were distributed and collected over a three weeks time period.

\section{Analyses and Results}

A total of 110 questionnaires were distributed. Of 110 questionnaires, 100 were completed in full. Ten questionnaires were rejected as they were not fully answered. The respondents consisted of various age groups and levels of education. Four percent of the respondents were at the ages of 20 years and below, $42 \%$ between the ages of $21-30$ years, $34 \%$ between the ages of $31-40$ years, $14 \%$ between the ages of $41-50$ years, and $6 \%$ were at the ages of 51 years and above. Respondents' level of education was as follows: $11 \%$ had secondary education, $28 \%$ had some diploma degree, $54 \%$ had a bachelor's degree, $6 \%$ had a Master's degree, and $1 \%$ had a Ph.D. degree. Twenty one percent of the respondents came from the Garments industry, 26\% from Education, $17 \%$ from Wholesale and Retail, 20\% from Hotel and Restaurant, 7\% from Printing and Communication, 4\% from Public Administration, and $5 \%$ from Health and Medical services.

\subsection{Reliability Analysis}

The reliability of the factors was checked using Cronbach's alpha. A Cronbach's alpha of 0.65 or higher [Nunnally 1978] was used as an acceptable value for internal consistency of the measures. The Cronbach's alpha of the dependent variable (Adoption of M-commerce) is 0.72 . The Cronbach's alphas for independent variables range from 
0.70 to 0.88 . These values support the contention that all the factors had adequate reliability. The reliabilities of the factors are shown in Tables 3.

\subsection{Regression Analyses}

Regression Analyses were used to test the proposed hypotheses. This study has one dependent variable, six independent variables, and one moderating variable. Summated scores of the respective factors were used to obtain the scores for all the measures. The runs test, Levene's test and Kolmogorov-Smirnov tests were conducted to test for randomness, constancy of variance, and normality, respectively. These tests show that there is no evidence of violation of the assumptions underlying multiple regression analysis. Also, there is no evidence of multicollinearity because the VIFs and condition indices are within acceptable levels. Table 4 presents the results of the regression analyses. The coefficient of $\mathrm{R}^{2}$ is 0.430 indicating that all the independent variables account for $43 \%$ of the variance in adoption of M-commerce. Durbin Watson of 2.010 indicates there is no auto-correlation problem.

The results of multiple regression analyses (Table 4) show that pricing and cost, rich and fast information, and security and privacy are significant predictors of adoption of M-commerce. These findings support three hypotheses (H3, H4, and H5). The results also show insufficient evidence for support of three hypotheses (H1, H2, and H6), suggesting that awareness and knowledge, convenience of mobile and WAP/GPRS devices, and perceived usefulness play insignificant roles in predicting the adoption of M-commerce.

The overall summary of the analysis for the moderating variable, self-efficacy, is also shown in Table 4 . The $\mathrm{R}^{2}$ value is 0.430 when no moderating variable is taken into account. This value increases to 0.548 when self-efficacy is considered as a moderator. The increase implies that the moderating variable contributes to strengthen the relationship between the independent variables and dependent variable. This means that self-efficacy when included as a moderator the model is able to explain $54.8 \%$ of the variance in the dependable variable - adoption of $\mathrm{M}$-commerce. The significance of the moderating variable of self-efficacy on the dependent variable is found to be high ( $\mathrm{p}$ value $=0.013$ ). The beta term for this moderated model between self-efficacy, and rich and fast information was found to be significant at 0.042 . This significant value implies that self-efficacy moderates the relationship between rich and fast information, and adoption of M-commerce services. This supports H11 that states that self-Efficacy has a significant moderating effect on the relationship between rich and fast information, and the adoption of M-commerce services.

However, the effect of sself-efficacy does not significantly moderate the relationships between (1) awareness \& knowledge ( $\mathrm{p}$ value $=0.214)$ and the adoption of M-commerce services, $(2)$ convenience of mobile and WAP/GPRS enabled devices ( $\mathrm{p}$ value $=0.256$ ) and the adoption of M-commerce services, $(3)$ pricing $\&$ cost $(\mathrm{p}$ value $=0.458)$ and the adoption of M-commerce services, (4) security \& privacy ( $p$ value $=0.984$ ) and the adoption of M-commerce services, and $(5)$ perceived usefulness $(\mathrm{p}$ value $=0.278$ ) and the adoption of M-commerce services. We, therefore, reject hypotheses $\mathrm{H} 7, \mathrm{H} 8, \mathrm{H} 9, \mathrm{H} 10$ and $\mathrm{H} 12$.

\section{Discussion and Conclusion}

This study posited that the factors influencing the adoption of M-commerce were awareness and knowledge, convenience of mobile devices and WAP/GPRS enabled handsets, pricing and cost, security and privacy, rich and fast information, and perceived usefulness.

The degree of awareness and knowledge was not related as a critical factor to the adoption of M-commerce services in Bangladesh. This finding is contrary to the findings of various studies (e.g., Julias and Khasawneh, 2003; Electronic Commerce Resource Center of Thailand, 2002; Vrechopoukis et al., 2002). Awareness could encompass marketing and education in relation to the product, peer influence which creates the awareness, customer services provided by the company to educate users and consumer self-learning in attaining the knowledge. However, Awareness and Knowledge of M-commerce services is not an important factor in the context of adoption of M-commerce services among employed mobile phone users in Bangladesh.

A significant finding of this study is that the convenience of mobile and WAP/GPRS enabled devices does not have a significant impact towards the adoption of M-commerce services. This partially contradicts the findings of many studies (e.g., Haque, 2004; Electronic Commerce Resource Center of Thailand, 2002; Vrechopoukis et al., 2002) that suggest that the convenience of mobile and WAP/GPRS enabled devices is a key factor of adoption.

The result of this study suggests that the pricing and cost is a significant factor of the adoption of M-commerce services. This supports several previous studies (e.g., Jillbert and Ahmad, 2003; Haque, 2004; Electronic Commerce Resource Center of Thailand, 2002; Vrechopoukis et al., 2002), in which researchers have found that the pricing and cost is the highest or commonly used factor to determine the adoption of M-commerce services.

This study suggests that the security and privacy is a significant factor of the adoption of M-commerce services. 
This is supported by various previous studies such as Jillbert and Ahmad (2003), Haque (2004), Vrechopoukis et al. (2002), Mariga (2003), and Huei (2004).

The rich and first information is found to be strongly correlated to the adoption of M-commerce services. This supports the findings by Jillbert and Ahmad (2003), Electronic Commerce Resource Center of Thailand (2002), Haque (2004), and Anckar and D'Incau (2002).

Perceived usefulness was not found to be an important factor in influencing people to adopt M-commerce services. This contradicts the findings by Jillbert and Ahmad (2003), Mariga (2003), Huei (2004), and Saga and Zmud (1984).

Self-efficacy has a positive moderating effect on the relationship between the rich \& fast information and the adoption of M-commerce services. It has no significant moderating effect on the relationships of the rest of the independent variables - Awareness and knowledge, Convenience of mobile devices, Pricing \& Cost, Security \& Privacy and Perceived Usefulness - with the dependent variable - Adoption of M-commerce services.

\section{Limitations and Future Direction}

In this study, our objective was to investigate the major factors influencing the adoption of M-commerce services among mobile users in Bangladesh with the moderating effect of self-efficacy. Although the factors identified in this study were based on the extant literature, we acknowledge that future studies may look at more related constructs to form a more comprehensive picture of the adoption of M-commerce services in Bangladesh. Similarly, future studies may also include more moderating and/or mediating constructs to the model presented in this paper.

This study provides future researcher with several avenues. Future work can examine whether the gender difference has any significant influence on the M-commerce adoption level. Further, researchers can also attempt to investigate the moderating effects of different age groups of the user on the M-commerce adoption in Bangladesh. We hope this study provides an impetus for researchers to continue investigation in this area.

\section{References}

ABIresearch. (2010). Shopping by Mobile will Grow to $\$ 119$ Billion in 2015, ABIresearch: Technology Market Intelligence, February 16, 2010. Accessed online on July 15, 2010 from http://www.abiresearch.com/press/1605-Shopping+by+Mobile+Will+Grow+to+\%24119+Billion+in+2015.

Anckar, B. \& D'Incau, D. (2002). Value-Added Services in Mobile Commerce: An Analytical Framework and Empirical Findings from a National Consumer Survey.

Angsana, A. T. (2002). International diffusion of M-commerce: A Coupled-hazard approach, Thesis written at University of Minnesota for the Department of Information and Decision Sciences Carlson School of Management.

Bandura, A. (1977). Self-Efficacy: Toward a unifying theory of behavioral change, Psychology Review, Vol. 84: 191-215.

Bax, S., and McGill, T.J. (2003). Predicting web page development success: An exploratory study, 14th Australasian Conference on Information Systems, 26-28 November, Perth, W.A.

Davis, F.D. (1989). Perceived usefulness, perceived ease of use, and user acceptance of information technology, MIS Quart., Vol. 13: 318-339.

Fishbein, M., and Ajzen, I. (1975). Belief, attitude, intention and behavior: An introduction to theory and behavior, Addison-Wesley, Reading, MA.

Gartner Dataquest (2005). Forecast: Mobile terminals, worldwide, 2000-2009, Gartner Dataquest, July 18, 2005. Accessed online on July 4, 2008 from http://www.gartner.com/DisplayDocument?id=483696.

Gist, M.E. (1989). The influence of training method of Self-Efficacy and idea generation among managers, Pers. Psychology, Vol. 42: 787-805.

Haque, A., 92004). Mobile commerce: Customer perception and its prospect on business operation in Malaysia, The Journal of American Academy of Business, Cambridge, March 2004.

Heinonen, K., 92002). Acceptance of mobile services-insight from the Swedish market for mobile telephony, SSE/EFI Working Paper Series in Business Administration No 2002: 16.

Hossain, M.M., and Prybutok, V.R. (2008). Consumer Acceptance of RFID Technology: An Exploratory Study, IEEE Transactions on Engineering Management, Vol. 55, No. 2: 316-328.

Huei, P.V. (2004). The study on the acceptance of wireless computing devices among consumers in Penang, Unpublished MBA thesis, Nottingham Trent University. Olympia College, Penang, Malaysia. 
Jillbert, J. and Ahmad, K. (2003). Adoption, diffusion, use and impact of m-commerce within campus community: a survey of international students, Proceedings of the 15th Annual SPUSC 2003: The Drive to be Different, Newcastle University, Australia.

Kotler, P. (2002). Marketing Management. The Millennium edition ( $10^{\text {th }}$ ed.). Prentice Hall International, Inc.

Leung, C.H., Chan, Y.Y., \& Chan, C. (2003). Analysis of Mobile Commerce, Hong Kong ACM 1-58113-788-5/03/09 ICEC, Pittsburgh, PA.

Lewis, D., \& Bridger, D. (2000). The soul of the new consumer: Authenticity - what we buy and why in the new economy, Nicolas Brealey Publishing, London.

Loh, S. (2004). M-commerce Survey. Retrieved December 30, 2004 from http://unsw.fissure.org/mcomm/.

Mariga, J. R. (2003). Managing E-Commerce and Mobile Computing Technologies, Purdue University. USA.

Nunnally, J.C. (1978). Psychometric theory, Second edition, McGraw-Hill, New York.

Panis, S., Morphis, N., Felt, E., Reufenheuser, B., Bohm, A. and Nitz, J. (2001). Mobile commerce service scenarios and related business models, EURESCOM project P1102 eMpoiro, Cyprus Telecommunications Authority, T-Systems Nova, Germany and Elisa Communications Corporation, Finland.

Rao, M. (2004). EM-Wire: E-Commerce, M-commerce poised for rapid take-off in Europe, Electronic Markets: The International Journal of Electronic Commerce \& Business Media, April 6, 2002. Retrieved September 22, 2004 from http://www.electronicmarket.com.

Rettie, R., \& Brum, M.M. (2001). M-commerce: The role of SMS text messages, Thesis from Kingston University. UK.

Rosa, G., Marisa, S., \& Maria, J.P. (2001). Moderator effects of self-efficacy on occupational stress, Psychology in Spain, Vol. 5, No. 1: 63-74.

Saga, V.L., \& Zmud, R.W. (1994). The nature and determinations of IT acceptance, routinization and infusion, Proceedings of the IFIP TC8 working conference on diffusion, transfer and implementation of information technology. North Holland.

Saljoughi, F. (2002). Adoption of M-commerce, Master thesis, Information and Communication Technology, Agder University College in Grimstad, Norway.

Shuster, T. (2001). Pocket internet and m-commerce: How will it fly? Working paper, George Washington University, Washington, DC.

Tang, J., \& Veijalainen, J. (2001). Using Agents to Improve Security and Convenience in Mobile E-Commerce, Proceedings of the $34^{\text {th }}$ Hawaii International Conference of System Sciences, IEEE Computer Society Press, Los Alamitos.

Vittet-Philippe, P. \& Navarro, J.M. (2009). Mobile e-business (M-commerce): State of play and implication for European enterprise policy, European Commission Enterprise Directorate-General E-Business Report, December 6, 2000. Accessed online on August 21, 2009 from www.ncits.org/tc_home/v3htm/v301008.pdf.

Vrechopoukis, A. P., Constanton, F.D. \& Sideris, I. (2004). Strategic marketing planning for mobile commerce diffusion and consumer adoption, The eBusiness Center, Department of Management Science and Technology, Athens University of Economics and Business. Retrieved October 12, 2004 from http://www.eltrun.aueb.gr/cvs/sideris/mCommerce_Diffusion.pdf.

Wooe, R.E., \& Bandura, A. (1989). Impact of conceptions of ability of self-regulatory mechanisms and complex decision making, Journal Pers. Social Psychology, Vol. 56: 407-415.

Table 1. Mobile phone subscribers in Bangladesh (Up to April, 2009)

\begin{tabular}{|l|c|}
\hline Mobile Operator & No. of Subscribers (in Millions) \\
\hline Grameen Phone Ltd. (GP) & 20.31 \\
\hline Banglalink & 9.46 \\
\hline Aktel & 7.85 \\
\hline Citycell & 1.70 \\
\hline Teletalk Bangladesh Ltd. & 1.07 \\
\hline Warid Telecom International & 3.31 \\
\hline Total & $\mathbf{4 3 . 7 0}$ \\
\hline
\end{tabular}


Table 2. M-commerce services offered by mobile phone operators in Bangladesh

\begin{tabular}{|l|c|c|c|c|c|c|}
\hline Service & Aktel & $\begin{array}{c}\text { Bangla } \\
\text { Link }\end{array}$ & Citycell & $\begin{array}{c}\text { Grameen } \\
\text { Phone }\end{array}$ & Tele Talk & $\begin{array}{c}\text { Warid } \\
\text { Telecom }\end{array}$ \\
\hline FnF (Friends and Family) & Yes & Yes & Yes & Yes & Yes & Yes \\
\hline SMS & Yes & Yes & Yes & Yes & Yes & Yes \\
\hline International SMS & Yes & Yes & Yes & Yes & Yes & Yes \\
\hline Internet SMS & N/A & N/A & N/A & Yes & Yes & N/A \\
\hline Voice SMS & Yes & Yes & Yes & Yes & Yes & Yes \\
\hline Voice Mail & Yes & Yes & Yes & Yes & Yes & Yes \\
\hline Voice Chatting & N/A & Yes & Yes & N/A & N/A & N/A \\
\hline SMS Chatting & Yes & Yes & N/A & Yes & N/A & N/A \\
\hline SMS E-mail & Yes & Yes & Yes & Yes & Yes & Yes \\
\hline GPRS/EDGE Internet & Yes & Yes & Yes & Yes & Yes & Yes \\
\hline WAP & Yes & Yes & Yes & Yes & Yes & Yes \\
\hline MMS & Yes & Yes & Yes & Yes & Yes & Yes \\
\hline Instant Recharging & Yes & Yes & Yes & Yes & Yes & Yes \\
\hline Call Back Service & N/A & Yes & N/A & Yes & N/A & N/A \\
\hline Welcome Tunes & Yes & Yes & Yes & Yes & N/A & Yes \\
\hline Song Dedication & Yes & Yes & Yes & N/A & N/A & N/A \\
\hline Voice Based Service & Yes & Yes & N/A & Yes & Yes & Yes \\
\hline Missed Call Alert & Yes & Yes & N/A & Yes & N/A & Yes \\
\hline Push-Pull Service & Yes & Yes & Yes & Yes & Yes & Yes \\
\hline Power Menu & Yes & Yes & N/A & N/A & N/A & N/A \\
\hline International Roaming & Yes & Yes & Yes & Yes & Yes & Yes \\
\hline Economy ISD & Yes & Yes & Yes & Yes & Yes & Yes \\
\hline Online Customer Care & Yes & Yes & Yes & Yes & N/A & N/A \\
\hline
\end{tabular}

Table 3. Summary of Reliability Analysis

\begin{tabular}{|l|l|l|l|}
\hline Variables & Number of items & Items deleted & Cronbach's alpha \\
\hline Awareness and Knowledge & 5 & None & 0.74 \\
\hline $\begin{array}{l}\text { Convenience of Mobile Devices and } \\
\text { WAP/GPRS }\end{array}$ & 5 & None & 0.88 \\
\hline Pricing and Cost & 5 & None & 0.77 \\
\hline Security and Privacy & 5 & None & 0.77 \\
\hline Rich and Fast information & 5 & None & 0.70 \\
\hline Perceived Usefulness & 5 & None & 0.85 \\
\hline Self-Efficacy & 5 & None & 0.83 \\
\hline Adoption of M-commerce & 5 & None & 0.72 \\
\hline
\end{tabular}


Table 4. Results of Hierarchical Regression Analyses

\begin{tabular}{|l|l|l|l|}
\hline Variables & Beta & t-values & Significance \\
\hline Model 1 & & & \\
\hline Awareness and Knowledge & 0.098 & 2.619 & 0.295 \\
\hline Convenience of Mobile Devices and WAP/GPRS enabled & 0.103 & 1.033 & 0.304 \\
\hline Pricing and Cost & 0.321 & 3.428 & $0.001^{*}$ \\
\hline Security and Privacy & 0.205 & 2.033 & $0.045^{*}$ \\
\hline Rich and Fast information & 0.263 & 2.745 & $0.007^{*}$ \\
\hline Perceived Usefulness & -0.100 & -1.003 & 0.318 \\
\hline Model 2 & & & \\
\hline Awareness and Knowledge & 0.272 & 2.383 & $0.019^{*}$ \\
\hline Convenience of Mobile Devices and WAP/GPRS enabled & 0.045 & 0.483 & 0.630 \\
\hline Pricing and Cost & 0.036 & 0.460 & 0.647 \\
\hline Security and Privacy & 0.052 & 0.505 & 0.615 \\
\hline Rich and Fast information & 0.257 & 2.492 & $0.014^{*}$ \\
\hline Perceived Usefulness & 0.272 & 2.646 & $0.010^{*}$ \\
\hline Self-efficacy & 0.292 & 2.544 & $0.013^{*}$ \\
\hline Self-efficacy - Awareness and Knowledge & -0.781 & -1.252 & 0.214 \\
\hline $\begin{array}{l}\text { Self-efficacy - Convenience of Mobile Devices and } \\
\text { WAP/GPRS enabled }\end{array}$ & 0.645 & 1.144 & 0.256 \\
\hline Self-efficacy - Pricing and Cost & & & \\
\hline Self-efficacy - Security and Privacy & 0.348 & 0.746 & 0.458 \\
\hline Self-efficacy- Rich and Fast information & -0.010 & -0.020 & 0.948 \\
\hline Self-efficacy- Perceived Usefulness & 1.421 & 2.066 & $0.042^{*}$ \\
\hline & -0.729 & -1.093 & 0.278 \\
\hline
\end{tabular}

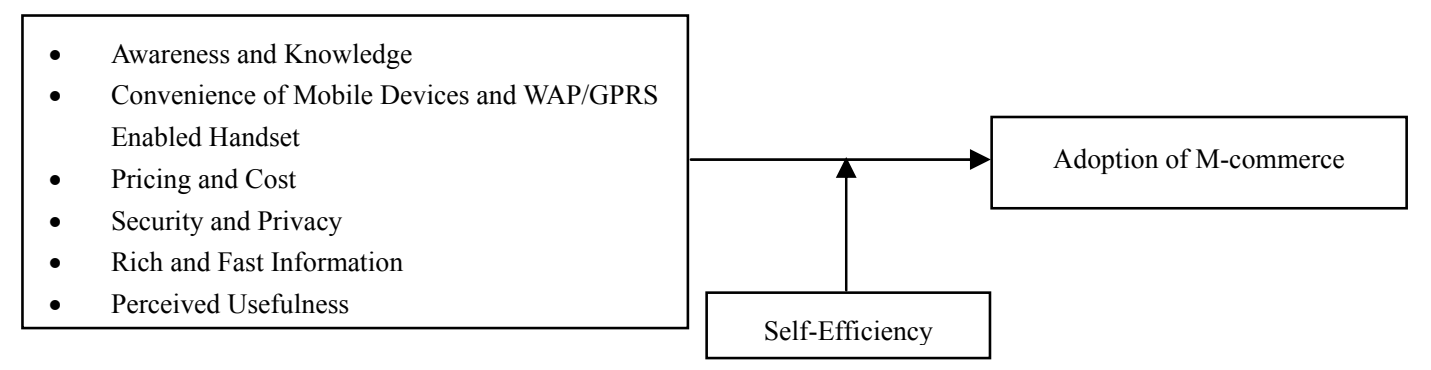

Figure 1. Research Model for the Adoption of M-commerce 